\title{
Cash Transfers and Poverty Reduction in Chile*
}

\author{
Claudio A. Agostini and Philip H. Brown
}

August 2007

\begin{abstract}
By all accounts, poverty in Chile has declined dramatically over the last 20 years, with the national headcount ratio declining from nearly 40\% in 1987 to below 14\% in 2006. Due to data limitations, most research on poverty in Chile has focused on national and regional estimates, yet recent improvements in poverty mapping methodologies now enable the analysis of poverty at the sub-regional level. In this paper, we employ these methodologies to assess the impact of cash transfers on poverty rates at the county level. We find that transfers significantly reduce the incidence of poverty and that estimated headcount ratios fall by between $5 \%$ and $68 \%$. To better understand variation in the effectiveness of transfers in reducing poverty at the local level, we also explore the interplay between transfers and geography. We find that the greatest reductions in poverty at the county level occur in rural households and that topography influences the effectiveness of transfers in some areas. Taken together, these findings suggest that targeting at low levels of aggregation can help to deliver further reductions in poverty.
\end{abstract}

JEL Codes: H53, I32, O15, D63

\footnotetext{
${ }^{*}$ We thank Chris Elbers, Berk Özler and Gabriel Demombynes for multiple clarifications and discussions regarding the methodology employed in this analysis. We are also grateful to Jason Long for programming help, to iSciences for map design and support, and to Diana Paola Góngora for capable research assistance. We also thank the Universidad Alberto Hurtado and the Colby College Division of Social Sciences for financial support. Finally, Philip H. Brown acknowledges the International Food Policy Research Institute for sabbatical support during the preparation of the manuscript.
}

Agostini: Ilades-Universidad Alberto Hurtado, Santiago, Chile; agostini@uahurtado.cl Brown: Colby College, 5246 Mayflower Hill, Waterville, ME 04901, USAñ phbrown@ colby.edu 


\section{Introduction}

Chile's dramatic increase in income over the last 20 years has been matched by an equally dramatic reduction in poverty: while GDP per capita increased from US\$ 1,679 in 1987 to US\$ 7,214 in $2006,{ }^{1}$ the proportion of Chileans living below official poverty lines fell from $39.4 \%$ to $13.7 \%$ (Figure 1). Although economy-wide growth explains much of the reduction in poverty rates in the past (Larrañaga, 1994; Contreras, 2003), a series of cash and in-kind transfers from the government to poor households also proved to be fundamental to poverty alleviation (Beyer, 1997; Valdés, 1999). ${ }^{2}$

Current estimates of poverty (as measured by the headcount ratio) range from $11.2 \%$ in copper-rich Region II to $29.7 \%$ in largely-agricultural Region IX. ${ }^{3}$ However, these simple statistics obscure the profound economic diversity found within each of Chile's 13 regions. For example, mining accounts for between 57 and $65 \%$ of the Region II's total economic activity (and 95\% of its exports), but copper and other economically important minerals are concentrated in Calama, Ollague, and other counties in the region's mountainous northeast. By contrast, Mejillones, Tocopilla, and other coastal counties have felt the economic impact of declines in the Chilean fish flake and saltpeter industries since the early part of this decade (Government of Antofagasta 2007). In Region IX, growth in tourism and cellulose production in recent decades has primarily benefited resort communities in the Andes and lumber-producing areas in the coastal mountains, respectively, while the Central Valley has seen limited investment and a

\footnotetext{
${ }^{1}$ In purchasing Power Parity terms, GDP per capita rose from $\$ 3,608$ in 1987 to $\$ 12,737$ by 2006 .

${ }^{2}$ Cowen and De Gregorio (1996) argue that even though a one percentage point increase in growth rates was associated with a 0.4 percentage point reduction in poverty between 1990 and 1994, it is difficult to separate the pure effect of growth from the impact of government transfers because social policy affects economic growth.

${ }^{3}$ Chile is comprised of 13 administrative regions. Each has a formal name and a Roman numeral, the latter generally used. The numbers are assigned sequentially from north to south, with the exception of Region XIII (the Santiago Metropolitan Region), which is located between Regions V and VI. Each region consists of multiple provinces, which are further divided into 342 communes, i.e., counties. Each county has its own government except Antártica, which is governed by Cabo de Hornos County. In this paper, we focus on the remaining 341 independent counties.
} 
decline in the sugar beet industry (Government of Araucanía, 2007). Such variation in economic and geographic conditions implies that there exists a wide distribution of poverty within regions, and uncovering this distribution may have important consequences for the design of social policy.

Unfortunately, the Chilean census does not include income data, and no survey with detailed income data is representative below the regional level in Chile. Thus, Contreras (1996, 2001), Contreras and Ruiz-Tagle (1997), Feres (2000), Pizzolito (2005a, 2005b), and others who have studied poverty and income distribution in Chile have restricted their analyses to the national and regional levels, where estimates of income are statistically reliable. However, recent developments in methodologies for combining survey and census data now enable the estimation of statistically-reliable measures of poverty at the sub-regional level. ${ }^{4}$

In this paper, we employ the poverty-mapping methodologies formalized by Elbers, et al. (2003) to assess the impact of cash transfers on poverty rates at the county level, two administrative units below the regional level. We find that cash transfers result in economicallyand statistically-significant reductions in county-level poverty rates across Chile. However, the estimated reductions in headcount ratios range from $5.1 \%$ to $67.8 \%$, indicating that there is considerable variation in the effectiveness of cash transfers in bringing people out of poverty. To better understand this variation, we also explore the interplay between transfers and geography. We find that the greatest reductions in poverty occur in rural areas, although urban concentration and topography both appear to influence the effectiveness of cash transfers on poverty within regions, suggesting that geographic considerations may be useful for improving targeting performance. This evidence is consistent with the theoretical predictions described by Besley

\footnotetext{
${ }^{4}$ Hentschel, et al. (1999) estimate geographically-disaggregated poverty rates in Ecuador by imputing income from survey data for every individual in the census. Elbers, Lanjouw, and Lanjouw (2003) improve upon these povertymapping methods by incorporating errors from the first stage to obtain more precise estimates of income. These methods have been applied to South Africa (Demombynes and Özler 2006) and Cambodia, Ecuador, and Madagascar (Elbers, et al. 2007), and elsewhere.
} 
and Kanbur (1990) and with empirical evidence from Cambodia, Ecuador, and Madagascar reported by Elbers, et al. (2007).

The remainder of this paper is organized as follows: section 2 provides a brief overview of the poverty mapping methodology proposed by Elbers, et al. (2003) and discusses its implementation in the Chilean context; section 3 describes government programs for poverty reduction in Chile, including the various subsidies available to poor households; section 4 describes the data used in the analysis; section 5 presents the empirical results; and section 6 concludes.

\section{Methodology}

The methodology proposed by Hentschel, et al. (2000) and developed by Elbers, et al. (2003) takes advantage of the detailed data in household surveys and the universal coverage of censuses. The intuition is conceptually straightforward: household income is estimated using survey data, restricting the explanatory variables to those available in both the survey and a census from a similar point in time. These parameters are then used to estimate income for the entire population based on the census data. Finally, poverty indicators are estimated for geographic areas for which the census is representative but for which the survey is not.

The execution of the method is somewhat more complicated. We provide a brief overview here and a detailed accounting in Appendix 1; readers who are interested in the complete statistical properties of the estimators are referred to Elbers, et al. (2003). First, a detailed household survey is used to estimate the joint distribution of household income and a vector of explanatory variables. Restricting the set of explanatory variables to those available in the census, these "first stage" estimates are then used to generate the distribution of income for 
any subgroup of the population, conditioning on the observed characteristics of that subgroup. The simplest means of estimating the model is via a linear approximation of the conditional expectation, allowing geographic effects and heteroskedasticity in the distribution of the error term. It is important to note that the cluster component of the residual can significantly reduce the power of the estimates in the second stage, so it is important to explain the variation in income due to location via observable variables to the greatest extent possible; stepwise regression is therefore used to derive the best-fitting specification for each of Chile's 13 regions independently.

The result of this first-stage estimation is a vector of coefficients, a variance-covariance matrix associated with this vector, and a set of parameters that describe the distribution of the errors. The second stage utilizes this set of parameters along with the characteristics of the individuals or households in the census in order to generate predicted values of income and the relevant errors. For these effects, bootstrapping is used to simulate values of household income. The complete set of simulated values is then used to calculate the expected value of poverty for each subgroup. This procedure is repeated 250 times, taking a new set of coefficients and errors for each simulation. The mean and standard deviations of these coefficients constitute the point estimates and standard deviations for the poverty indicator, respectively.

Finally, the standard error of the poverty indicator must be estimated as accurately as possible in order to infer precise conclusions from the estimates. As shown in Appendix 1, the prediction error has three components: the first is given by the presence of a stochastic error in the first stage model, which implies that the actual income of the household deviates from its expected value (idiosyncratic error); the second is determined by the variance of the first stage parameter estimators (model error); and the third is given by the use of an inaccurate method to 
calculate the estimator of the poverty indicator (computation error). The idiosyncratic error falls proportionately with the size of the population in each area. This component of the error rises with lower levels of geographic disaggregation, limiting the extent of disaggregation possible. The model error is determined by the properties of the first stage estimators; its magnitude thus depends only on the precision of the first stage parameter estimates. For this reason, we made every effort to obtain the best fit in the first-stage regression. The computation error falls by increasing the number of simulations. We specify 250 simulations to reduce this component of the error as much as possible. ${ }^{5}$

\section{Public Policy for Poverty Reduction in Chile}

Beginning in the early 1980s, the government adopted a wide-ranging set of policies to reduce poverty. Central to the government's anti-poverty policy was the development of a standardized metric to identify poor households. The "CAS Card" (revised and renamed the "CAS-2 Card" in 1987) is administered by the county at the household's request; it evaluates poverty on the basis of self-reported income and housing criteria, particularly construction materials, density, and access to potable water. A score is assigned to the household and remains valid for three years, at which point a re-evaluation may be requested. ${ }^{6}$

The CAS Card became the primary data point for setting government priorities in the provision of public housing, with the concentration of poor households in any given region in 1982 and 1992 directly influencing the allocation of housing subsidies over the subsequent decade (Soto and Torche 2004). Between 1990 and 2000, housing subsidies increased at an average rate of $10 \%$ per year in real terms, and poor neighborhoods received additional subsidies

\footnotetext{
${ }^{5}$ There are no significant gains in efficiency by further increasing the number of repetitions.

${ }^{6}$ Soto and Torche (2004) provide additional details on the CAS form and the classification of poor households.
} 
to develop public sewerage and electric systems on the basis of these criteria. These criteria were also used to identify indigent households eligible for receiving direct cash transfers.

Government subsidies to poor households fall into five main programs:

1. Family Subsidy (SUF): A subsidy provided to pregnant women, parents with children not covered by social security, and parents or guardians of persons with physical disabilities. Eligibility is determined by the CAS-2 Card. This program is administered by individual counties, but the budget is assigned by the regional governments according to the distribution of CAS-2 Card scores in each county. The benefit was $\mathrm{CH} \$ 4,126$ per month $^{7}$ per recipient in 2003, and it is indexed to inflation.

2. Assistance Pensions (PASIS): Pensions provided for adults aged 65 and over, physicallydisabled adults, and mentally-disabled individuals regardless of age who have a total income below half of the minimum pension allowance. ${ }^{8}$ These transfers are only available to individuals who have at least three continuous years of residency in Chile and who do not receive any other pensions. The regional government evaluates households for eligibility based on the CAS-2 Card score; however, because the number of subsidies available to each region is fixed by the Social Security Commission, the cutoff score varies by region (and, potentially, by county). In 2003, the benefit totaled CH\$ 45,091 per month for the physically disabled and twice that amount for the mentally disabled; it, too, is indexed to inflation.

3. Chile Solidario: A program that includes both cash and counseling services for indigent and high-risk households, particularly those with female heads. Eligibility is determined by the CAS-2 Card. During the first phase of the program, beneficiaries receive a monthly payment that decreases from $\mathrm{CH} \$ 10,500$ to $\mathrm{CH} \$ 4,126$ over 24 months (2003 rates), conditional on frequent meetings with counselors to learn budgeting, goal-setting, and employment skills; counselors also offer guidance on other support programs for which the household may be eligible. After two years, beneficiaries who have successfully completed the counseling program are automatically enrolled in the SUF program for up to 36 months.

4. Water and Sewage Subsidy (SAP): A three-year, renewable subsidy to offset the cost of water among poor households. Eligibility is determined by the CAS-2 Card. Although the program is administered by the county government, the Ministry of Finance sets the budget available to each region and regional governments set the number of subsidies available to each county; as such, the cut-off score may vary by county. This subsidy covers between $20 \%$ and $85 \%$ of the cost of water for up to 15 cubic meters per month; it is paid directly to water providers and discounted from the water bills of beneficiaries.

\footnotetext{
${ }^{7}$ In 2003, US\$ $1=$ CH\$ 691.4 on average.

${ }^{8}$ The minimum monthly pension allowance was CH\$ 8,9715 in 2006.
} 
5. Unemployment: A decreasing monthly payment for up to 12 months for individuals who lost work through no fault of their own. Eligibility is based on formal employment for at least 52 weeks during the previous two years ${ }^{9}$ and not having rejected job opportunities offered by the National Training and Employment Service or the county government. Although the CAS-2 Card is not used to assign this subsidy, it is designed with the intention of preventing households from falling into poverty as a result of employment shocks. In 2003, the benefit was $\mathrm{CH} \$ 17,338$ the first 3 months, decreasing to $\mathrm{CH} \$$ 11,560 for the next three months and to $\mathrm{CH} \$ 8,669$ the last 6 months of eligibility.

Table 1 provides summary statistics for the number of recipients in each of Chile's 13 regions in 2003. Nearly 954,000 individuals (6.3 per cent of the population) receive the Family Subsidy each month. Almost $13 \%$ of the people living in Region IX benefit, while fewer than 2.3\% of households in region XII do. By contrast, only 3,682 individuals received Unemployment transfers each month on average, although this is at least partially due to the fact that the government replaced the transfer with mandatory unemployment insurance for those starting new jobs since 2002; this transfer is therefore no longer a policy tool for addressing poverty. The average monthly value of Unemployment payments is $\mathrm{CH} \$ 11,491$. Assistance Pensions dwarf the other subsidies, with an average benefit of $\mathrm{CH} \$ 45,059$. However, only $2.8 \%$ of Chile's population receives these transfers. The distribution of this subsidy is similar to that of the Family Subsidy.

The Solidarity Subsidy and Water and Sewage Subsidy are provided to households rather than individuals. Approximately $1.1 \%$ of households receive the former, with the greatest share in Regions III and VII. The average monthly value of the Solidarity Subsidy is CH $\$ 9,842$. The Water and Sewage Subsidy is allocated to almost $16 \%$ of households, and it is particularly prevalent in the arid north of Chile (Regions I, II, III, and IV) and in Region XI. Unlike many other subsidies, the value of the Water and Sewage Subsidy varies by region, with beneficiaries

\footnotetext{
${ }^{9}$ For self-employed workers, eligibility is based on 12 consecutive months of contributions to social security in the previous two years.
} 
in Regions I, II, and XI receiving far greater subsidies than households elsewhere, reflecting the cost of purchasing and transporting water in these areas. ${ }^{10}$

Weighting household subsidies by the mean number of household members in each region, the total expected monthly value of all subsidies for a representative person ranges from CH\$ 966 in Region XIII to $\mathrm{CH} \$ 3,595$ in Region XI; the national average is $\mathrm{CH} \$ 1,708$. According to Chilean law, taxes cannot be tied to individual expenditures, so there is no specific financing for cash transfers to poor households. Therefore, transfers are financed out of total tax revenues. In 2003, 51.6\% of total tax revenues came from the Value Added Tax, $27.4 \%$ from income taxes, $12.1 \%$ from excise taxes, $4.5 \%$ from tariffs, and $4.4 \%$ from transaction taxes.

Figure 2 shows the distribution of average transfers by type by pre-transfer income decile. As the figure suggests, cash transfers have good targeting on average. Nevertheless, the top half of the income distribution receives a significant share of transfers, including transfers for which such households are technically ineligible. Thus, there is considerable room for improvement in targeting.

\section{Data}

The survey employed to impute income as described above is the November 2003 Characterizacion Socioeconomica Nacional (CASEN), administered by the University of Chile on behalf of the Ministry of Planning. The survey utilizes multistage random sampling with regional stratification and clustering. In the first stage, the country is divided between rural and urban areas for each of the 13 regions, and the primary sampling units are selected according to a probability sample based on the 2002 census. Within each sampling unit, households are

\footnotetext{
${ }^{10}$ For example, the cost of drinking water is up to 66 per cent higher than the national average in Region XI despite heavy rainfall in the area.
} 
selected with equal probability. ${ }^{11}$ The final sample includes 68,153 households comprising 257,077 people. These households represent 315 of the 342 counties in Chile, with as few as 49 and as many as 315 households surveyed in each county. The nationally representative survey allows for two forms of disaggregation: the survey is representative for all households by region and for urban and/or rural households at the national level. Although the Ministry of Planning purports that the CASEN is also representative for 301 self-reporting counties, scholars (e.g., Valdés 1999; Contreras, et al. 2001; Pizzolito 2005b) widely agree that the survey is not representative at the sub-regional level. ${ }^{12}$

The CASEN includes detailed income data for individuals and households, including cash transfers from the government. The Economic Commission for Latin America and the Caribbean (ECLAC) corrects these data for reporting errors and discrepancies as summarized in Appendix 2 and detailed in ECLAC, IPEA, and UNDP (2002). The survey also includes data on demographic characteristics of household members, living conditions, ownership of durable goods, access to sanitation, and health and education characteristics. Using the CASEN alone to estimate poverty at low levels of aggregation yields weak results that allow for few conclusions given the magnitude of the errors. For example, the estimated headcount ratio among urban households in San Nicolás County (which is nominally representative at the county level) in Region VIII is $48.1 \%$, but with a standard error of $12.6 \%$, the $95 \%$ confidence interval of $[23.4 \%, 72.8 \%]$ is too wide to describe poverty with any precision. In response to these problems, Agostini, Brown, and Góngora (2007) advocate the use of poverty mapping methodologies to impute income for everyone in the census using the 2003 CASEN. For the same county, they

\footnotetext{
${ }^{11}$ Further methodological details are provided by Pizzolito (2005).

${ }^{12}$ Even if the CASEN was representative, the standard errors for poverty estimated at the county level are so large that estimated changes in poverty are statistically insignificant. Nevertheless, Santibáñez (2006) compares headcount ratios at the county level in 2000 and 2003 to conclude that poverty decreased in 184 counties and increased in 106 others. Without considering standard errors, however, such conclusions are statistically unreliable.
} 
estimate the urban headcount ratio to be $48.4 \%$, with a $95 \%$ confidence interval of $[40.3 \%, 56.6 \%]^{13}$

The 2002 Chilean census collects data from 4,112,838 households comprising 15,545,921 individuals. The data include demographic characteristics of household members, living conditions, ownership of durable goods, access to sanitation, and health and education characteristics, but neither income nor consumption. Following Elbers, et al. (2003), a set of variables common to both the CASEN and census is used to impute income. Although some explanatory variables are defined identically in both data sets, others were constructed; in such cases, the means and variances of the explanatory variables were evaluated to ensure that they are identically defined. Using stepwise regression to detect the best fit for rural and urban households in each region separately, we determined that household demographics (e.g., the number of household members; the share of young children in the household), characteristics of the household head (e.g., gender; education level; ethnicity), characteristics of the house itself (e.g., number of rooms; construction material; type of flooring; water source; sewerage), and asset ownership (e.g., washing machine; water heater; fixed telephone; cellular phone; satellite or cable television; microwave; computer; Internet access) were the strongest predictors of household income. Estimates also included location dummies to capture latent cluster-level effects. The predictive ability of the model is high for cross-sectional data, with $R^{2}$ values ranging between 0.28 and 0.54 (Agostini, et al. 2007).

\footnotetext{
${ }^{13}$ To cite other examples, the estimated headcount ratio and associated $95 \%$ confidence interval using the CASEN alone is 23.6\% [-3.9\%,51.2\%] for Yerbas Buenas County and 39.7\% [28.6\%,50.8\%] for Pitrufquén County. The corresponding figures from Agostini, et al. (2007) are 42.3\% [31.8\%,51.7\%] for Yerbas Buenas and $39.7 \%$ [36.1\%,43.2\%] for Pitrufquén.
} 


\section{Empirical Results}

Using the coefficients and the variance-covariance matrix estimated as described above, we calculate poverty rates in each of Chile's 342 counties. Because Chile's rural and urban poverty lines differ, headcount ratios are estimated separately for rural and urban households, and a weighted average of the rural and urban poverty rates is reported. Table 2 provides summary statistics of the estimates and Figures 3 through 6 illustrate these estimates graphically. In each figure, the left and right panels depict the estimated headcount ratio prior to the receipt of cash transfers from the government and after the receipt of transfers, respectively. Darker shading indicates higher poverty rates within the county. Pre-transfer estimates of poverty range from $1.6 \%$ in the Santiago suburb of Vitacura to $54.3 \%$ in Pemuco (Region VIII); post-transfer estimates of poverty vary from $1.4 \%$ in Vitacura to $48.7 \%$ in Los Álamos County (Region VIII).

Poverty in Chile displays strong regional patterns. For example, poverty rates before the receipt of cash transfers are generally lowest in counties in Regions II and XII, both of which are rich in natural resources. By contrast, the median pre-transfer poverty rate is highest for Regions IV, VIII, and IX, which are largely dependent on agriculture for income. Just over $25 \%$ of the people in the largely urban counties of Regions V and XIII live below the poverty line. Countylevel variation in poverty rates is greatest in Regions XII and XIII and lowest in Region VI.

The Chilean Constitution stipulates that taxes cannot be directly tied to expenditures, so cash transfers for poverty reduction are financed out of total tax revenues. Because Chile's value added tax contributes over half of the country's tax revenue and because income tax data are not made available by the Chilean Internal Revenue Service, it is difficult to assess the tax burden of individual households, and thus the impact of taxes on poverty. It may therefore be the case that taxes exacerbate poverty. Indeed, inasmuch as consumption taxes are regressive, our estimates 
of the impact of cash transfers may be biased upward given the lack of information about financing. ${ }^{14}$ Nevertheless, there exists tremendous heterogeneity in poverty within regions, even if headcount ratios in poor areas are overstated.

Cash transfers to poor households have a profound impact on poverty rates in Regions I, IV, VII, VIII, and IX, where transfers induce a $17.3 \%$ reduction in the share of the population living in poverty in the median county. These effects are greater still in Regions X, XI, and XII, where the median county sees a $23.0 \%$ reduction in poverty from transfers. By contrast, cash transfers have a modest impact on the median headcount ratio in Regions II, V, and XIII. Still, the variance of the distribution of the estimated impact is high in Regions II, XI, and XII, suggesting that the effect of cash transfers varies widely even in regions where the median effect is comparatively high or comparatively low.

To examine the overall impact of cash transfers on poverty more formally, we also estimate the non-parametric density of the county-level headcount ratios before and after cash transfers using the Epanechnikov Kernel estimator. As Figure 7 shows, cash transfers shift the distribution of headcount ratios to the left, implying that cash transfers are effective in reducing poverty. Moreover, the Kolmogorov-Smirnov test for equality of distribution functions formally rejects the hypothesis that the two distributions come from the same data-generating process at the $99 \%$ confidence level. ${ }^{15}$

We repeat the Kolmogorov-Smirnov test for equality of pre-transfer and post-transfer headcount ratios separately for rural and urban poverty. Distributions based on the

\footnotetext{
${ }^{14}$ For this reason, our estimates must be considered as measuring the impact of cash transfers on after- tax income and not as the net impact of cash transfers on poverty.

${ }^{15}$ The first step of the test does not reject the hypothesis that the distribution of headcount ratios associated with pretransfer incomes contains smaller values than the distribution of headcount ratios associated with pre-transfer incomes. The second step of the test rejects the hypothesis that the distribution of headcount ratios for total income contains larger values than the distribution of headcount ratios for autonomous income. As a result, the joint test rejects the hypothesis that the two distributions are equal.
} 
Epanechnikov Kernel estimator are shown in Figures 8 and 9. The Kolmogorov-Smirnov test rejects the equality of distributions at the $99 \%$ confidence level in both cases, confirming that cash transfers have reduced poverty in both rural and urban areas. As the nonparemetric estimates show, the pre-transfer and post-transfer distributions of poverty in rural areas are quite different from those in urban areas, ${ }^{16}$ suggesting that urban concentration also influences the effectiveness of transfers within regions.

Given the variation in the effectiveness of transfers in reducing poverty within regions and between rural and urban areas, we also investigate the role of geography in poverty reduction using regression analysis. Specifically, we estimate:

$$
\begin{aligned}
\% \triangle H C R & =\beta_{0}+\beta_{1} U R B S H+\beta_{2} P O P+\beta_{3} M O U N T A I N+\beta_{4} V A L L E Y+\beta_{5} R A I N \\
& +\beta_{6} \text { REGION }+\beta_{7}(\text { REGION } \times U R B S H)+\varepsilon
\end{aligned}
$$

where $\% \triangle H C R$ is the percentage change in the headcount ratio based on the weighted estimates of poverty for rural and urban households in each county ${ }^{17}$ and $U R B S H$ is the percentage of households in the county classified as being urban. $P O P$ is the $\log$ of county population. MOUNTAIN and VALLEY are dummy variables for whether the county lies above 1500 meters in elevation and whether the county is principally located in Chile's Central Valley, respectively, and RAIN is a dummy indicating that the county experiences extreme rainfall (i.e., locales that receive less than $200 \mathrm{~mm}$ of rain per year and those that receive less than more than $1,750 \mathrm{~mm}$ of rain per year). These controls are important because the housing criteria included in the CAS-2 Card assessment of poverty differ across climactic zones. REGION is a vector of dummies that account for variation in the budgets received from the central government, for the ability of regional governments to efficiently allocate funding for poverty relief to counties, and for other

\footnotetext{
${ }^{16}$ Indeed, the Kolmogorov-Smirnov test also rejects the hypothesis that the distribution of the reduction in headcount ratios is the same for rural and urban areas.

${ }^{17}$ For robustness, we also estimate this equation using the absolute change in headcount ratios at the dependent variable, controlling for pre-transfer headcount ratios. These estimates are similar to those reported below.
} 
forms of unobserved heterogeneity that is common to all counties within the region. We further interact the region dummies with the urban share variable to estimate the impact of heterogeneity in urban concentration within regions. Heteroskedasticity-robust standard errors are bootstrapped 1,000 times to account for the fact that the dependent variable is estimated.

Because we cannot estimate a structural model that simultaneously determines poverty, transfers, and targeting, regression results should be interpreted as conditional correlations rather than causal determinants of the impact of cash transfers on poverty. In particular, we do not have data that allow us to explicitly evaluate local institutions (e.g., the ability of county governments to identify poor households) that may influence poverty rates. Nevertheless, the regressors explain a large fraction of the variance in the county data, with an $R^{2}$ of 0.96 .

A higher share in the urban population is associated with lower reductions in poverty in all 13 regions of Chile (Figure 3, Column 1). However, this effect varies widely by region: a one percentage point increase in the share of the urban population is associated with a $0.06 \%$ reduction in the change in headcount ratio derived from cash transfers in Region XIII (the omitted category) and a $0.27 \%$ reduction in Region XI. The effectiveness of cash transfers in reducing urban poverty especially lags behind that of rural poverty in counties in Regions II, III, $\mathrm{X}, \mathrm{XI}$, and XII. This result presents a more nuanced picture of poverty reduction than the regional estimates presented in Table 2, and suggests that it is insufficient to merely target rural poverty, urban poverty, or regional poverty, and that it is instead preferable to target rural or urban poverty within regions.

Conditioning on urban concentration, the results further show that transfers are correlated with a greater impact on poverty in more populous areas and in mountainous areas. By contrast, the effect of transfers on poverty is lower in Chile's Central Valley and in areas with extreme 
rainfall. As with the share of the population living in urban areas, the influences of topography, population density, and weather may differ by region. To begin to account for this possibility, we also interact region dummies with dummies for living in mountainous communities (Column 2). ${ }^{18}$ Indeed, we find that cash transfers are correlated with reduced poverty in mountainous areas in Regions I, II, III, VIII, XI, and XIII, but that mountainous areas appear to impede poverty reduction appears in Region VII. These results again suggest that efficiency gains in targeting poverty may be made from accounting for variation within regions.

\section{Discussion and Conclusion}

Since the early 1980s, the Chilean government has made poverty reduction an important policy objective. By the early part of this decade, Chile's antipoverty strategy had become exemplified by a series of transfers provided to pregnant women, poor parents, female heads of household, the elderly, the handicapped, the unemployed, the indigent, and those unable to purchase sufficient drinking water. Such transfers made a significant contribution to the $65 \%$ decline in poverty rates over the last 20 years.

While the national poverty rate was estimated to be $18.7 \%$ in 2003 , the CASEN survey demonstrated considerable heterogeneneity in poverty rates across regions. These disparities have influenced public policy, including the allocation of budgets for antipoverty programs. However, estimates of poverty at the regional level obscure the enormous variation in poverty rates within regions. Yet because the CASEN is not representative at the sub-regional level, scholars have not been able to accurately analyze poverty at the sub-regional level.

\footnotetext{
${ }^{18}$ Including interactions for region dummies and population, the dummy for Central Valley communities, and extreme rainfall produces similar results. However, the reduction in degrees of freedom caused by each additional set of interactions reduces the ability to identify separate geographic effects within regions.
} 
To better understand inter-regional differences in the effectiveness of transfers in poverty reduction, we employ poverty-mapping methodologies to assess the impact of cash transfers at the county level. Using nonparametric analysis and kernel estimation, we find a high level of heterogeneity in the extent to which transfers reduce poverty within each region. We also find sizable differences in poverty reduction between rural and urban areas. To further explore the interplay between transfers, poverty, and geography, we use regression analysis to show that the conditional impact of urban concentration on poverty reduction varies by as much as $350 \%$ between regions. The effect of topography also varies tremendously by region. For policymakers and scholars alike, it would be interesting to know the reasons underlying the wide disparities in the extent to which cash transfers reduce poverty within regions. One possibility is that the depth of poverty differs across communities and that relatively uniform transfers fail to reduce headcount ratios in some areas. Alternatively, it may be that the CAS-2 Card fails to identify some poor households. ${ }^{19}$ Third, the geographic distribution of the poor within communities may make targeting more or less difficult. Finally, it may be that institutional failures and/or elite capture of resources prevent transfers from reaching poor households even when they are correctly identified. Each of these possibilities remains an important topic of further research.

Even if the reasons underlying differences in the effectiveness of cash transfer are not well understood, however, it would be possible to evaluate the efficiency of targeting at the county level as opposed to the regional level. Such analyses would be timely because Chile realized a budget surplus totaling $7.9 \%$ of GDP in 2006 and $5.3 \%$ of GDP in the first half of

\footnotetext{
${ }^{19}$ Indeed, the government has already taken important steps to better target the poor by replacing the CAS-2 card with the "Social Protection Card" (SPC) in April 2007. The SPC uses income stability, educational level, labor experience, age structure, disabilities, health status, housing ownership, crowding, urban/rural location, and regional unemployment levels to identify poor households.
} 
2007, and the government has proposed allocating part of the surplus for additional poverty relief. As we have shown in this paper, including urban concentration, topography, and other geographic considerations within regions is likely to facilitate greater poverty reductions than targeting by region alone. 


\section{References}

Agostini, Claudio, Philip H. Brown, and Diana Paola Góngora (2007). "Estimadores de Pobreza en Chile a Nivel Comunal," Mimeo, University Alberto Hurtado.

Kanbur, Ravi and Timothy Besley (1990). “The Principles of Targeting." World Bank Policy Research Working Paper Series No. 385.

Beyer, Harald (1997). "Distribución del Ingreso: Antecedentes para la Discusión." Estudios Públicos 65: 5-58.

Contreras, Dante (1996). "Pobreza y Desigualdad en Chile: 1987-1992. Discurso, Metodología y Evidencia Empírica." Estudios Públicos 64: 57-94.

Contreras, Dante (2001). "Economic Growth and Poverty Reduction by Region: Chile 1990-96." Development Policy Review 19(3): 291-302.

Contreras, Dante (2003). "Poverty and Inequality in a Rapid Growth Economy: Chile 1990-96." Journal of Development Studies 39(3): 181-200.

Contreras, Dante and Osvaldo Larrañaga (1999). "Activos y Recursos de la Población Pobre en Chile." El Trimestre Económico 66(263): 459-500.

Contreras, Dante, Osvaldo Larrañaga, Julie Litchfield and Alberto Valdés (2001). "Poverty and Income Distribution in Chile 1987-1998: New Evidence." Cuadernos de Economía 114: 191208.

Contreras, Dante and Jaime A. Ruiz-Tagle (1997). "Como Medir la Distribución del Ingreso en Chile." Estudios Públicos 65: 59-80.

Cowan, Kevin and Jose de Gregorio (1996). "Distribución y Pobreza en Chile: ¿Estamos Mal? ¿Ha Habido Progresos? ¿Hemos Retrocedido?” Estudios Públicos 64: 27-56.

Demombynes, Gabriel and Berk Özler (2005). "Crime and Local Inequality in South Africa." Journal of Development Economics 76(2): 265-292.

Government of Antofagasta (2007). http://www.goreantofagasta.cl/goreantofagasta/ index.aspx?channel=4129. Accessed 8 August 2007.

Government of Araucania (2007). http://www.gorearaucania.cl/noticias.php?seccion=28. Accessed 8 August 2007.

Economic Commission for Latin America and the Caribbean, Instituto de Pesquisa Econômica Aplicada, and United Nations Development Program (2002). Meeting the Millennium Poverty Reduction Target in Latin America and the Caribbean. Santiago: ECLAC. 
Elbers, Chris, Tomoki Fujii, Peter Lanjouw, Berk Özler, and Wesley Yip (2007). "Poverty Alleviation Through Geographic Targeting: How Much Does Disaggregation Help?" Journal of Development Economics 83(2007): 198-213.

Elbers, Chris, Jean O. Lanjouw, and Peter Lanjouw (2003). "Micro-Level Estimation of Poverty and Inequality." Econometrica 71(1): 355-364.

Feres, Juan Carlos (2000). "La Pobreza en Chile en el año 2000." Serie Estudios Estadísticos y Prospectivos No. 14, CEPAL.

Hentschel, Jesko, Jean O. Lanjouw, Peter Lanjouw, and Javier Poggi (2000). "Combining Census and Survey Data to Trace the Spatial Dimensions of Poverty: A Case Study from Ecuador." World Bank Economic Review 14(1); 147-165.

Larrañaga, Osvaldo (1994). "Pobreza, Crecimiento y Desigualdad: Chile 1987-1992." Revista de Análisis Económico 9(2): 69-92.

Pizzolito, Georgina (2005a). "Monitoring Socio-Economic Conditions in Argentina, Chile, Paraguay, and Uruguay: Chile.” CEDLAS-World Bank Report, December.

Pizzolito, Georgina (2005b). "Poverty and Inequality in Chile: Methodological Issues and a Literature Review." Documento de Trabajo No. 20, CEDLAS.

Santibáñez, Claudio (2006). "Pobreza y Desigualdad en Chile: Antecedentes para la Construcción de un Sistema de Protección Social." Inter-American Development Bank, Serie de Estudios Económicos y Sociales RE1-06-004.

Soto, Raimundo and Arístides Torche (2004). "Spatial Inequality, Growth, and Migration in Chile." Cuadernos de Economía 41: 401-424.

Valdés, Alberto (1999), "Pobreza y Distribución del Ingreso en una Economía de Alto Crecimiento: Chile, 1987-1995." Estudios Públicos 75: 5-47. 


\section{Appendix 1}

This Appendix provides a brief overview of the methodology proposed by Hentschel, et al. (2000) and developed by Elbers, et al. (2003). In the first stage, a model is created that relates the income per capita of household $h\left(Y_{h}\right)$ in cluster $c$ with a group of observable characteristics $\left(X_{h}\right):$

$$
\ln Y_{h c}=E\left[\ln Y_{h c} \mid X_{h c}\right]+u_{h c}=X_{h c} \beta+u_{h c}
$$

where the error vector $u$ is distributed $\mathrm{F}\left(0, \sum\right)$. To allow correlation within each cluster, the error term is further assumed to consist of a cluster component $(\eta)$ and an idiosyncratic error $(\varepsilon)$ :

$$
u_{h c}=\eta_{c}+\varepsilon_{h c}
$$

The two components are assumed to be independent of each other and uncorrelated with the observable variables $X_{h c}$.

It is not necessary to specify a restrictive functional form for the idiosyncratic component of the error, $\sigma_{\varepsilon}^{2}$. Indeed, with consistent estimators of $\beta$, the residuals of the decomposition of the estimated error,

$$
\hat{u}_{h c}=\hat{u}_{. c}+\left(\hat{u}_{h c}-\hat{u}_{. c}\right)=\hat{\eta}_{c}+\hat{\varepsilon}_{h c}
$$

can be used to estimate the variance of $\varepsilon{ }^{20}$ The functional form commonly used for estimating the variance of the idiosyncratic error is:

$$
\sigma_{\varepsilon}^{2}=\left[\frac{A \hat{\varepsilon}^{z_{h c}^{T} \alpha}+B}{1+\hat{\varepsilon}^{z_{h c}^{T} \alpha}}\right]
$$

The upper and lower limits, $A$ and $B$, can be estimated together with the parameter $\alpha$ using the standard pseudo-maximum likelihood; the advantage of this approach is that it eliminates impossible values for the predicted variances.

\footnotetext{
${ }^{20}$ The subindex ".” in the equation represents the average over the index.
} 
The simplest means of estimating the model is to use a linear approximation of the conditional expectation, allowing geographic effects and heteroskedasticity into the distribution of the error term. It is important to note that the cluster component of the residual can significantly reduce the power of the estimates in the second stage, and that it is thus important to explain the variation in income or consumption due to location via observable variables to the greatest extent possible.

The result of this first-stage estimation is a vector of coefficients, $\beta$, a variancecovariance matrix associated with this vector, and a set of parameters that describe the distribution of the errors. The second stage utilizes this set of parameters along with the characteristics of the individuals or households in the census in order to generate predicted values of the log of income and the relevant errors. For these effects, bootstrapping is used to simulate values of income of each household or each individual. These simulated values are based on the prediction of the income and the error terms, $\eta$ and $\varepsilon$ :

$$
\hat{Y}_{h c}=\exp \left(X_{h c} \hat{\beta}+\hat{\eta}_{c}+\hat{\varepsilon}_{h c}\right)
$$

For each household, the two components of the error term are taken from the empirical distribution described by the parameters estimated in the first stage. The coefficients $\hat{\beta}$ are taken from a normal multivariate distribution described by the estimators of $\beta$ in the first stage and the associated variance-covariance matrix. The complete set of simulated values of $\hat{Y}_{h c}$ is then used to calculate the expected value of poverty or inequality measures by area. This procedure is repeated $n$ times, taking a new set of coefficients $\beta$ and errors for each simulation; for each geographic area, the mean and the standard deviation of the poverty indicator are calculated over the whole set of simulations, which constitute its point estimate and its standard deviation, respectively. 
We will call the poverty indicator $G\left(n_{c}, X_{c}, \beta, u_{c}\right)$, where $n_{c}$ is a $N_{c}$ vector of the number of household members in county $c, X_{c}$ is a $N_{c} x k$ vector of their observable characteristics, and $u_{c}$ is a $N_{c}$ error vector. Thus, the expected value of the poverty indicator is estimated given the characteristics of the individuals and the households and the model estimated in the first stage, i.e.:

$$
G_{c}^{E}=E[G \mid n, X ; \xi]
$$

where $\xi$ is the vector of parameters of the model, including the parameters that describe the distribution of the error term. Replacing the unknown vector $\xi$, with a consistent estimator $\hat{\xi}$, we get:

$$
G_{c}^{E}=E[G \mid n, X, \hat{\xi}]
$$

This conditional expected value is generally impossible to resolve analytically, making it necessary to use Monte Carlo simulations to obtain an estimator, $\tilde{G}_{c}^{E}$.

One complication associated with this methodology is calculating the correct standard errors, which is not trivial. Because it is not possible to calculate them analytically, the methodology again resorts to bootstrapping techniques and Monte Carlo simulations. Suppressing the subscripts, the difference between the estimator of the expected value of $G, \tilde{G}_{c}^{E}$, and the actual level of the poverty indicator for the geographic area can be decomposed into:

$$
G-\tilde{G}^{E}=\left(G-G^{E}\right)+\left(G^{E}-\hat{G}^{E}\right)+\left(\hat{G}^{E}-\tilde{G}^{E}\right)
$$

The prediction error thus has three components: the first is due to the presence of a stochastic error in the first stage model, implying that the actual household incomes deviate from their expected values (idiosyncratic error); the second is due to the variance in the estimators of the 
parameters of the model from the first stage (model error); and the third is due to the use of an inexact method to calculate $\hat{G}_{c}$ (computation error).

The variance of the estimator due to the idiosyncratic error shrinks proportionally with the population in each geographic area. Thus, smaller populations within each geographic area are associated with larger idiosyncratic errors, introducing a limit to the extent of disaggregation that may be achieved. The variance of the estimator due to the model error can be calculated using the delta method:

$$
V_{\text {Model }}=\nabla^{T} V(\hat{\xi}) \nabla
$$

where $\nabla=\left\lfloor\partial G^{E} / \partial \xi\right\rfloor, V(\xi)$ is the variance-covariance matrix of the first stage estimators, and $\hat{\xi}$ is a consistent estimator of $\xi$, also obtained from the first stage. This component of the predicted errors is determined by the properties of the first-stage estimators and therefore doesn't systematically change with the population in each geographic area; its magnitude depends only on the precision of the first-stage estimates. The variance of the estimator due to computational error depends on the computational methodology used. Since Monte Carlo simulations are employed here, it is possible to reduce this error component by increasing the number of simulations; we use 250 simulations to minimize the error component to the greatest extent possible.

The expected value of the poverty indicator coefficient is thus conditional on the first stage regression, the variance due to the idiosyncratic component of income per capita of the households, and the gradient vector. The Monte Carlo simulation generates 250 vectors of error terms from the distribution estimated in the first stage. With each set of vectors, the poverty indicator is calculated. Then, the expected value simulated for the poverty indicator is the average of the 250 responses: 


$$
\tilde{G}^{E}=\frac{1}{250} \sum_{d=1}^{250}\left(\hat{G}_{d}^{E}\right)
$$

The variance of $G$ is estimated using the same simulated values as:

$$
V_{\text {Model }}=\frac{1}{250} \sum_{d=1}^{250}\left(G_{d}-\tilde{G}^{E}\right)^{2}
$$

Finally, it is important to underscore the crucial assumption that the models estimated using survey data are applicable to the observations of the census. This assumption is reasonable enough if the year of the census and the survey coincide or are close. In the case of this particular study, the 2002 census is matched with the 2003 CASEN survey, making the assumption implicit in the methodology reasonable. 


\section{Appendix 2}

This Appendix describes the adjustments to the CASEN undertaken by ECLAC. See also ECLAC, IPEA, and UNDP (2002). Although any of these adjustments may theoretically introduce bias, Contreras and Larrañaga (1999) present evidence to the contrary.

The first type of adjustment made by ECLAC is related to non-response and invalid answers. In particular, ECLAC makes adjustments in three cases: people who declare themselves as employed but who do not report income from their main occupation; people who declared themselves to be retired or living on a pension but who do not report the amount of the pension; and households living in owner-occupied housing but who do not report a rental value. In the first and second case, ECLAC imputes the value of the mean income for each person based on family relationship, gender, educational attainment, occupation, type of economic activity, and region of residence. In the third case, ECLAC imputes an implicit rental value using the "hot deck" technique, wherein the data set is ordered geographically and households are selected based on the housing tenancy, the type of housing, and other household characteristics. By contrast, when households report a positive value for imputed rent despite not being owners, the value reported is subtracted from the household income.

ECLAC also adjusts for under- and over-reporting of some types of income. The procedure basically consists in adjusting income from specific sources to match corresponding values in the National Accounts System of the Central Bank of Chile's Households and Expenditures Account. To do this, the data from National Accounts is converted to match the income categories included in the CASEN. Then, the total values for each specific income category are compared to those in the CASEN. Finally, the proportional differences for each income category are imputed uniformly to each individual receiving income in the CASEN. There are two exceptions 
to this last step: adjustments to capital income are made only to the top quintile of households, and income from transfers and gifts are not adjusted at all. 
Figure 1. Poverty Rates in Chile: 1990-2006

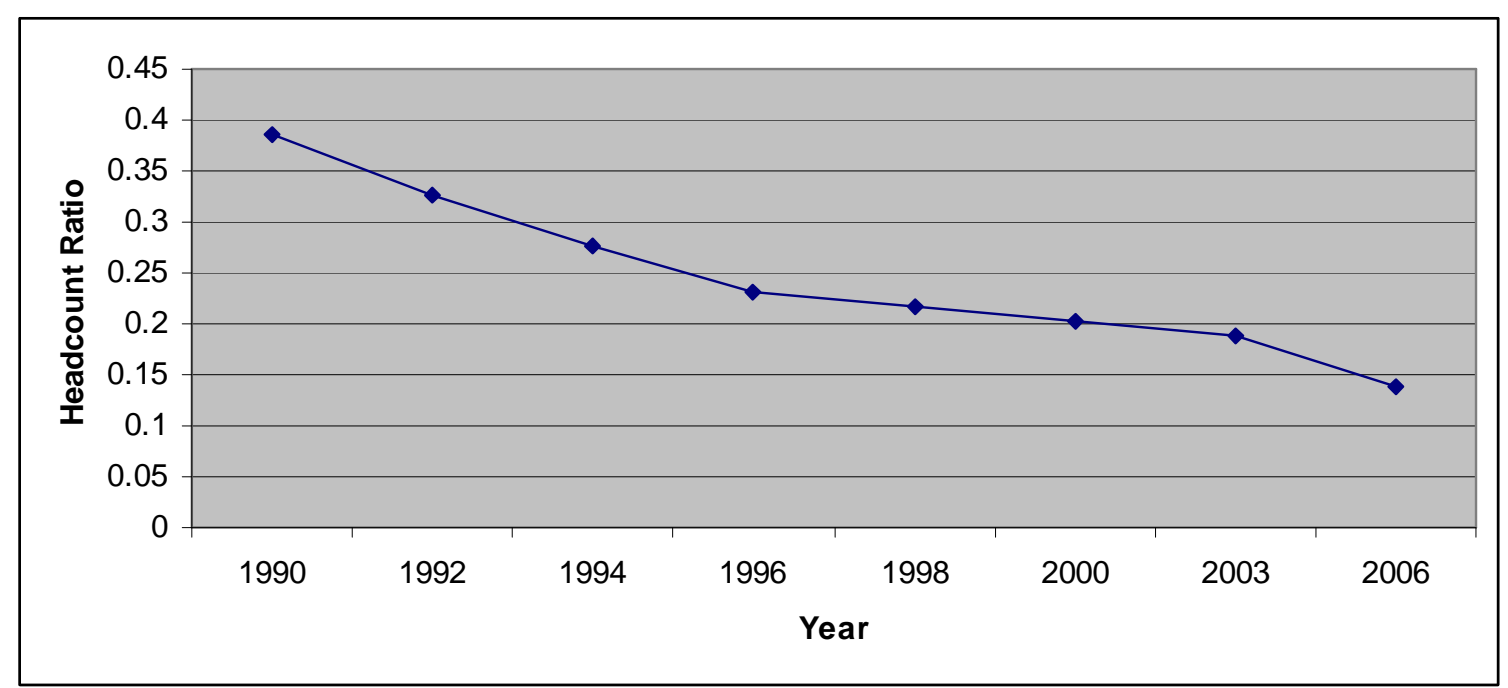

Figure 2. Cash Transfers by Income Decile

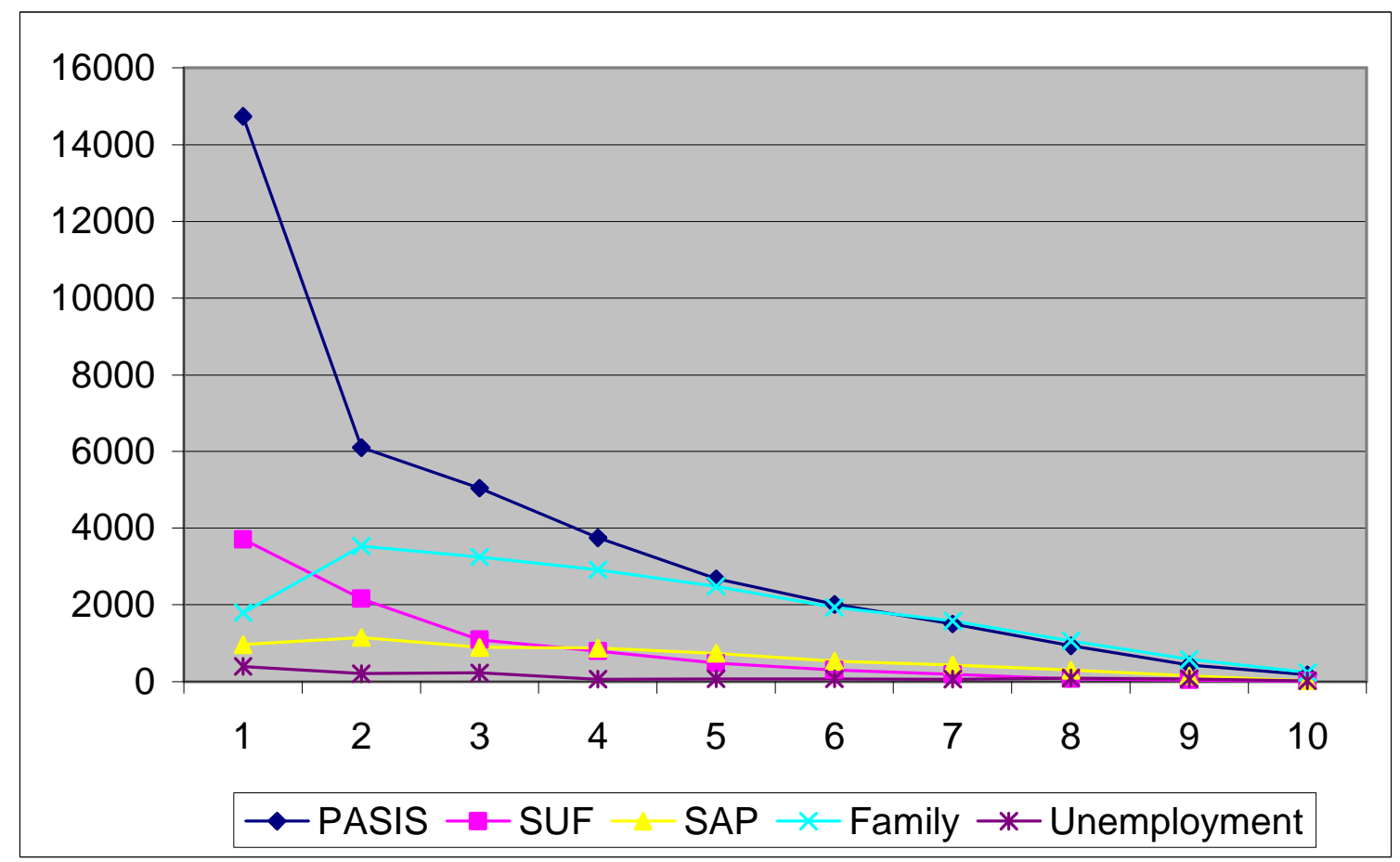


Figure 3. Pre-Transfer (Left) vs. Post-Transfer HCR (Right), Regions I, II, III, IV

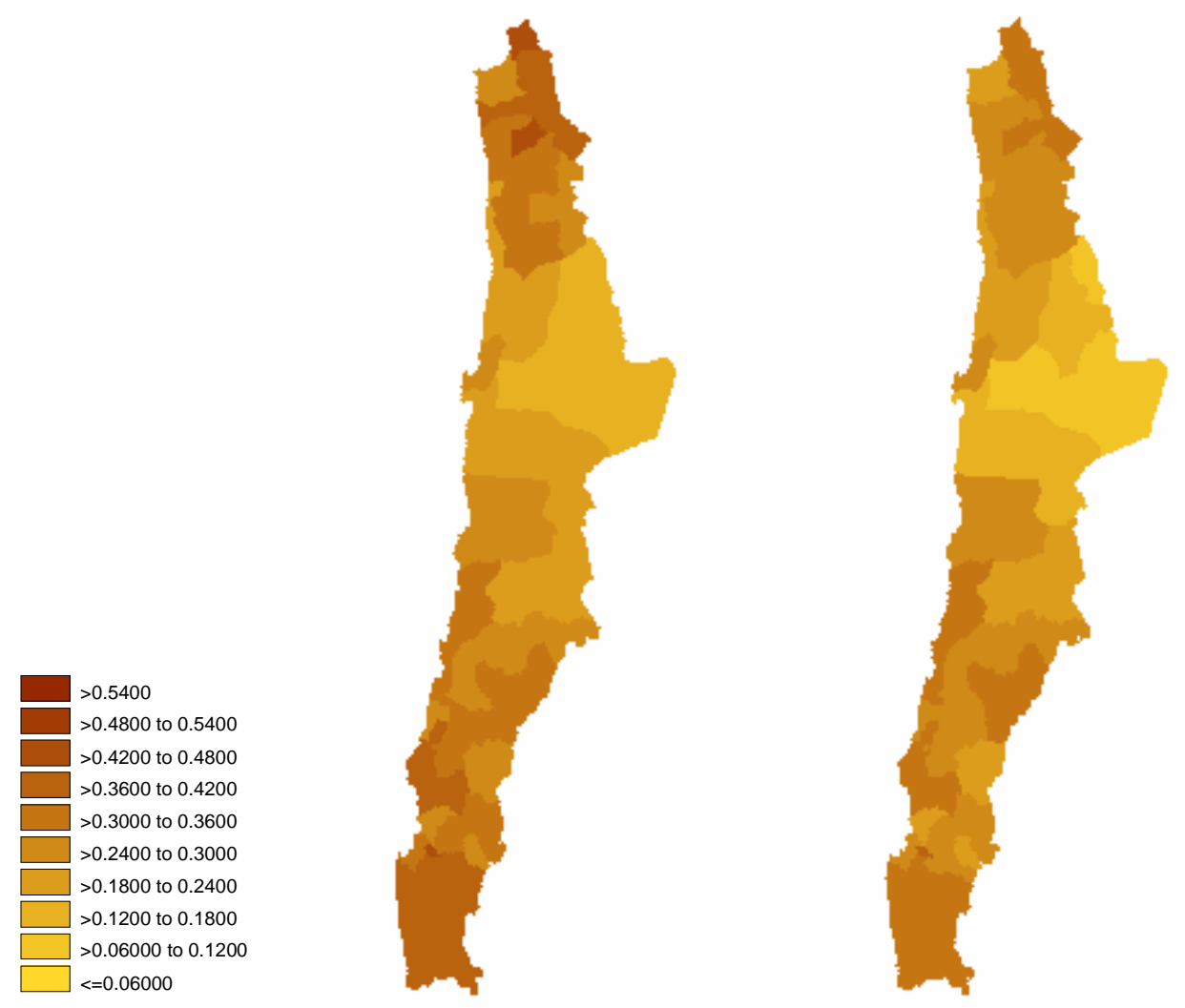


Figure 4. Pre-Transfer (Left) vs. Post-Transfer HCR (Right), Regions V, XIII

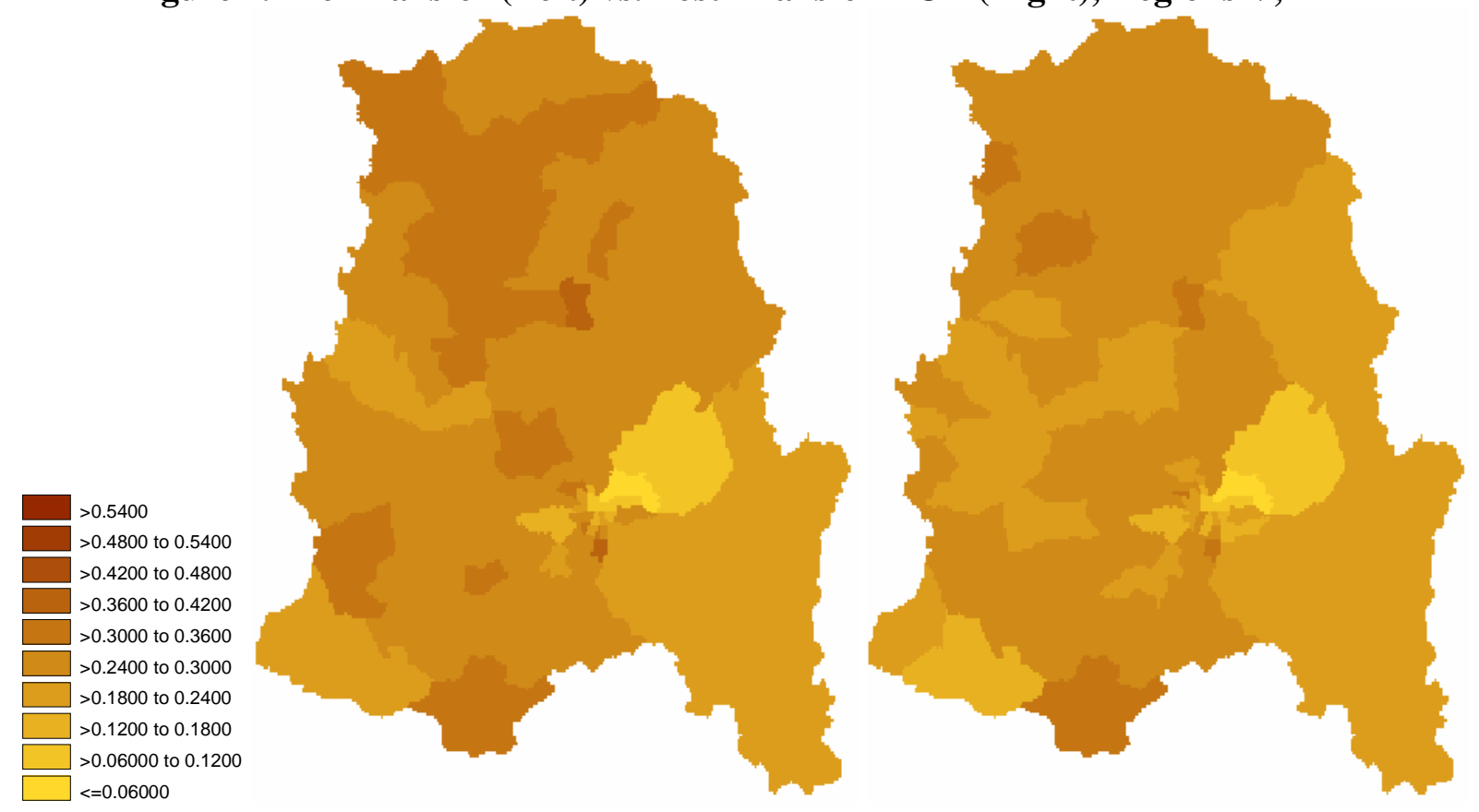

Figure 5. Pre-Transfer (Left) vs. Post-Transfer HCR (Right), Regions VI, VII, VIII, IX

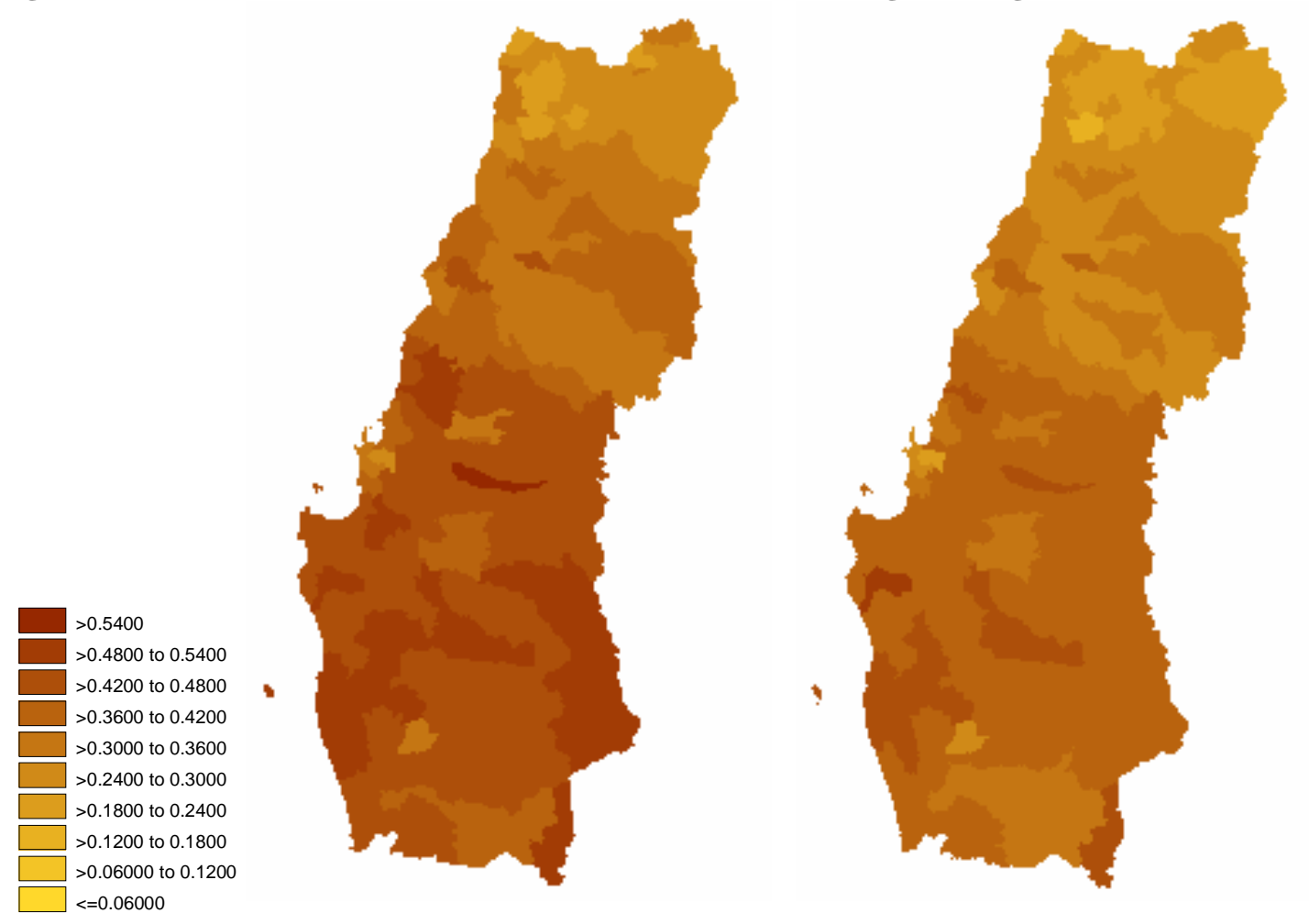


Figure 6. Pre-Transfer (Left) vs. Post-Transfer HCR (Right), Regions X, XI, XII

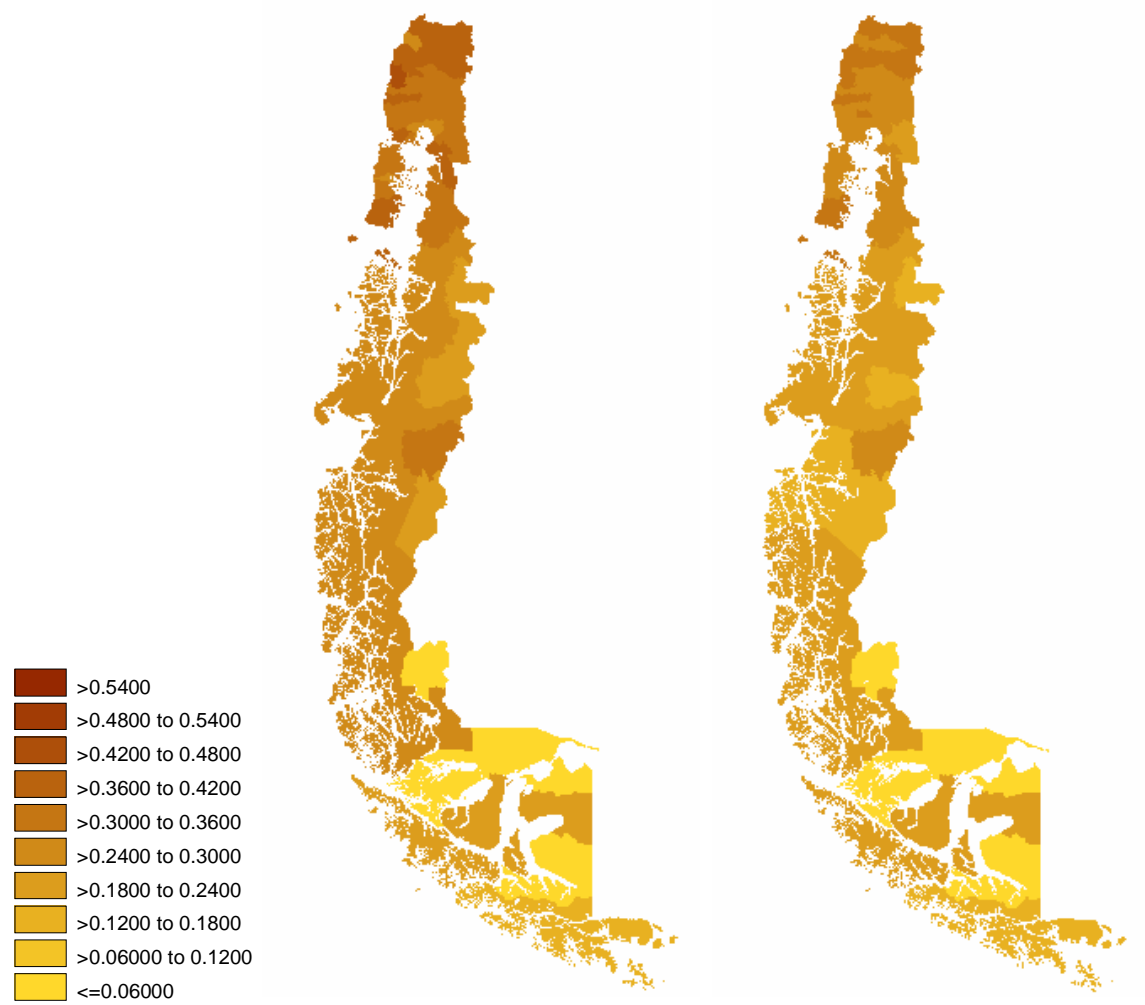

Figure 7. Kernel Density of the Distribution of Poverty, Pre- and Post-Transfer

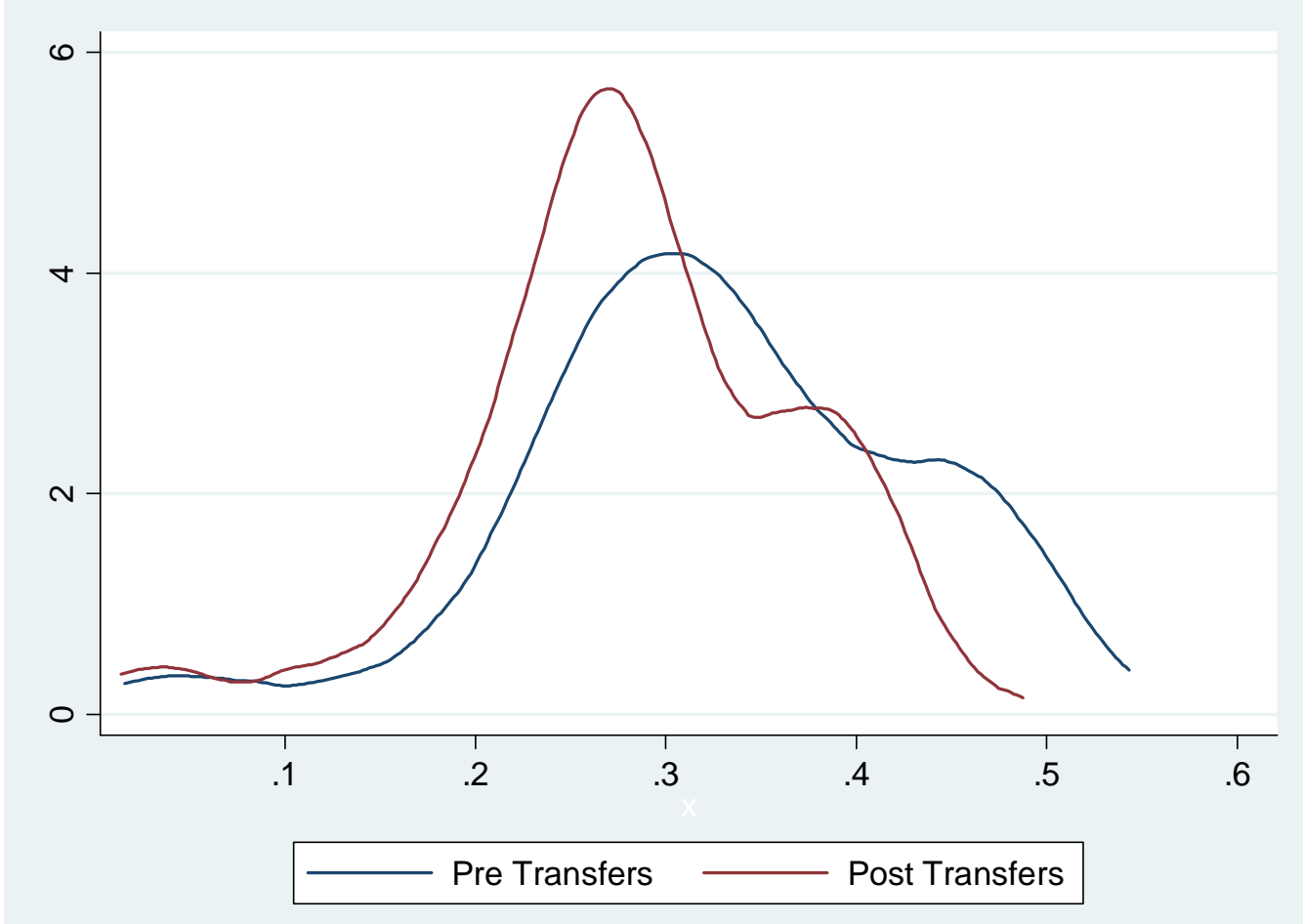


Figure 8. Kernel Density of the Distribution of Rural Poverty, Pre- and Post-Transfer

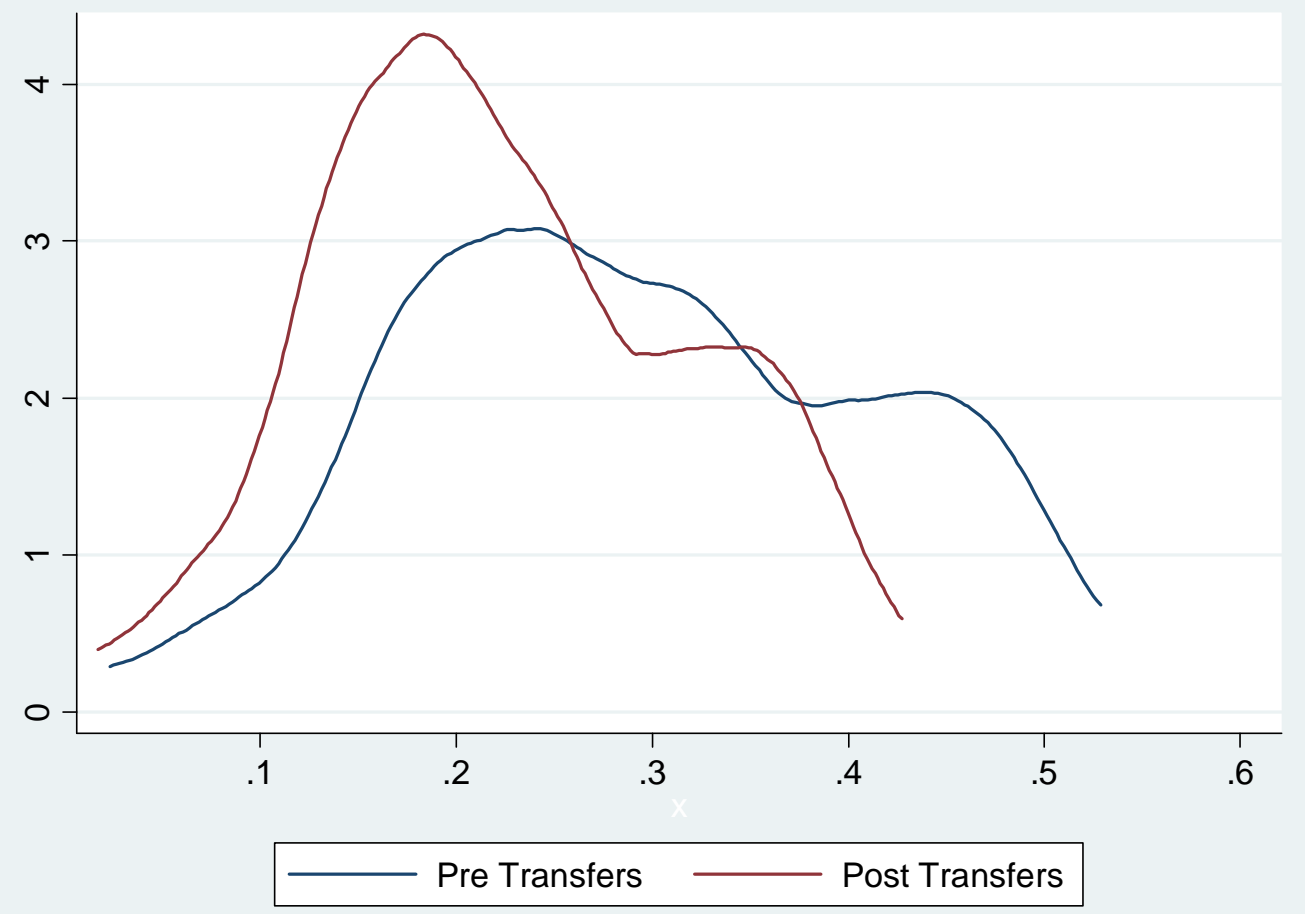

Figure 9. Kernel Density of the Distribution of Urban Poverty, Pre- and Post-Transfer

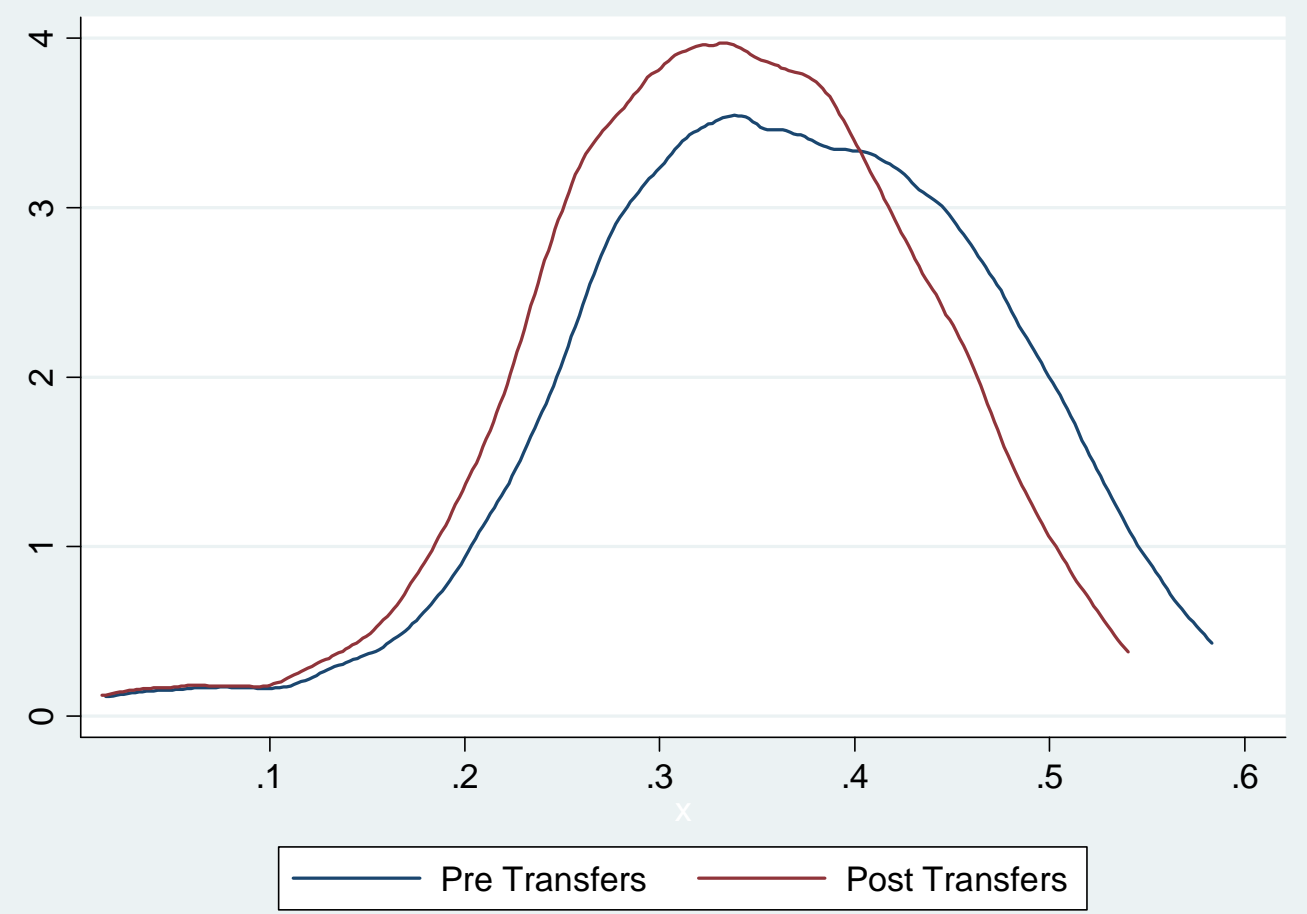


Table 1. Poverty-Reduction Transfers by Region

\begin{tabular}{|c|c|c|c|c|c|c|c|c|c|c|c|c|}
\hline \multirow[b]{2}{*}{ Region } & \multicolumn{4}{|c|}{ Family Subsidy ${ }^{\mathrm{A}}$} & \multicolumn{4}{|c|}{ Unemployment $^{\mathrm{A}}$} & \multicolumn{4}{|c|}{ Assistance Pensions ${ }^{\mathrm{A}}$} \\
\hline & Recipients $^{\dagger}$ & Share & Amount* & Average** & Recipients $^{\dagger}$ & Share & Amount* & Average** & Recipients $^{\dagger}$ & Share & Amount* & Average** \\
\hline I & 19,122 & $4.50 \%$ & $\$ 76,603$ & $\$ 4,006$ & 135 & $0.03 \%$ & $\$ 1,524$ & $\$ 11,291$ & 6,249 & $1.47 \%$ & $\$ 282,220$ & $\$ 45,163$ \\
\hline II & 15,454 & $3.21 \%$ & $\$ 61,169$ & $\$ 3,958$ & 47 & $0.01 \%$ & $\$ 540$ & $\$ 11,498$ & 5,862 & $1.22 \%$ & $\$ 263,641$ & $\$ 44,975$ \\
\hline III & 18,328 & $7.24 \%$ & $\$ 74,011$ & $\$ 4,038$ & 70 & $0.03 \%$ & $\$ 797$ & $\$ 11,388$ & 5,980 & $2.36 \%$ & $\$ 270,571$ & $\$ 45,246$ \\
\hline IV & 50,402 & $8.36 \%$ & $\$ 200,837$ & $\$ 3,985$ & 149 & $0.02 \%$ & $\$ 1,716$ & $\$ 11,514$ & 20,273 & $3.36 \%$ & $\$ 920,557$ & $\$ 45,408$ \\
\hline V & 81,648 & $5.33 \%$ & $\$ 326,416$ & $\$ 3,998$ & 519 & $0.03 \%$ & $\$ 6,053$ & $\$ 11,663$ & 32,502 & $2.12 \%$ & $\$ 1,461,835$ & $\$ 44,977$ \\
\hline VI & 52,494 & $6.77 \%$ & $\$ 208,443$ & $\$ 3,971$ & 114 & $0.01 \%$ & $\$ 1,297$ & $\$ 11,374$ & 23,730 & $3.06 \%$ & $\$ 1,065,764$ & $\$ 44,912$ \\
\hline VII & 100,010 & $11.05 \%$ & $\$ 396,176$ & $\$ 3,961$ & 144 & $0.02 \%$ & $\$ 1,651$ & $\$ 11,468$ & 30,825 & $3.40 \%$ & $\$ 1,388,065$ & $\$ 45,030$ \\
\hline VIII & 180,915 & $9.73 \%$ & $\$ 717,320$ & $\$ 3,965$ & 544 & $0.03 \%$ & $\$ 6,266$ & $\$ 11,517$ & 77,195 & $4.15 \%$ & $\$ 3,450,309$ & $\$ 44,696$ \\
\hline IX & 109,755 & $12.65 \%$ & $\$ 447,964$ & $\$ 4,081$ & 190 & $0.02 \%$ & $\$ 2,270$ & $\$ 11,949$ & 54,944 & $6.33 \%$ & $\$ 2,490,582$ & $\$ 45,329$ \\
\hline $\mathrm{X}$ & 117,391 & $11.01 \%$ & $\$ 471,432$ & $\$ 4,016$ & 203 & $0.02 \%$ & $\$ 2,358$ & $\$ 11,617$ & 56,699 & $5.32 \%$ & $\$ 2,570,569$ & $\$ 45,337$ \\
\hline XI & 8,732 & $9.70 \%$ & $\$ 35,546$ & $\$ 4,071$ & 9 & $0.01 \%$ & $\$ 109$ & $\$ 12,056$ & 4,144 & $4.61 \%$ & $\$ 187,565$ & $\$ 45,262$ \\
\hline XII & 3,296 & $2.23 \%$ & $\$ 13,059$ & $\$ 3,962$ & 29 & $0.02 \%$ & $\$ 342$ & $\$ 11,776$ & 2,107 & $1.43 \%$ & $\$ 96,191$ & $\$ 45,653$ \\
\hline XIII & 196,350 & $3.25 \%$ & $\$ 799,425$ & $\$ 4,071$ & 1,475 & $0.02 \%$ & $\$ 16,768$ & $\$ 11,368$ & 103,829 & $1.72 \%$ & $\$ 4,672,439$ & $\$ 45,001$ \\
\hline \multirow[t]{2}{*}{ Total } & 953,897 & $6.34 \%$ & $\$ 3,828,403$ & $\$ 4,013$ & 3,628 & $0.02 \%$ & $\$ 41,691$ & $\$ 11,491$ & 424,339 & $2.82 \%$ & $\$ 19,120,309$ & $\$ 45,059$ \\
\hline & \multicolumn{4}{|c|}{ Solidarity Subsidy ${ }^{\mathrm{B}}$} & \multicolumn{8}{|c|}{ Water Subsidy $^{\mathrm{B}}$} \\
\hline Region & Recipients $^{\dagger}$ & Share & Amount* & Average** & Recipients $^{\dagger}$ & Share & Amount* & Average** & \multicolumn{3}{|c|}{ Expected Value of Subsidy } & \\
\hline I & 1,690 & $1.51 \%$ & $\$ 16,739$ & $\$ 9,905$ & 32,595 & $29.14 \%$ & $\$ 181,758$ & $\$ 5,576$ & \multicolumn{3}{|l|}{$\$ 1,317$} & \\
\hline II & 910 & $0.73 \%$ & $\$ 8,749$ & $\$ 9,615$ & 37,787 & $30.45 \%$ & $\$ 276,450$ & $\$ 7,316$ & \multicolumn{3}{|l|}{$\$ 1,267$} & \\
\hline III & 1,683 & $2.45 \%$ & $\$ 16,425$ & $\$ 9,760$ & 25,355 & $36.91 \%$ & $\$ 87,661$ & $\$ 3,457$ & \multicolumn{3}{|l|}{$\$ 1,775$} & \\
\hline IV & 1,809 & $1.08 \%$ & $\$ 17,837$ & $\$ 9,860$ & 43,160 & $25.86 \%$ & $\$ 169,403$ & $\$ 3,925$ & \multicolumn{3}{|l|}{$\$ 2,173$} & \\
\hline $\mathrm{V}$ & 4,559 & $1.03 \%$ & $\$ 45,113$ & $\$ 9,895$ & 81,311 & $18.45 \%$ & $\$ 315,421$ & $\$ 3,879$ & \multicolumn{3}{|l|}{$\$ 1,408$} & \\
\hline VI & 2,562 & $1.20 \%$ & $\$ 24,642$ & $\$ 9,618$ & 33,872 & $15.81 \%$ & $\$ 90,136$ & $\$ 2,661$ & \multicolumn{3}{|l|}{$\$ 1,792$} & \\
\hline VII & 4,900 & $1.94 \%$ & $\$ 47,824$ & $\$ 9,760$ & 63,292 & $25.10 \%$ & $\$ 133,662$ & $\$ 2,112$ & \multicolumn{3}{|l|}{$\$ 2,173$} & \\
\hline VIII & 6,612 & $1.31 \%$ & $\$ 65,342$ & $\$ 9,882$ & 103,670 & $20.61 \%$ & $\$ 368,358$ & $\$ 3,553$ & \multicolumn{3}{|l|}{$\$ 2,478$} & \\
\hline IX & 3,815 & $1.60 \%$ & $\$ 38,189$ & $\$ 10,010$ & 52,692 & $22.11 \%$ & $\$ 139,084$ & $\$ 2,640$ & \multicolumn{3}{|l|}{$\$ 3,595$} & \\
\hline$X$ & 4,881 & $1.65 \%$ & $\$ 48,541$ & $\$ 9,945$ & 50,919 & $17.21 \%$ & $\$ 194,525$ & $\$ 3,820$ & \multicolumn{3}{|l|}{$\$ 3,083$} & \\
\hline XI & 371 & $1.44 \%$ & $\$ 3,710$ & $\$ 10,000$ & 9,253 & $36.01 \%$ & $\$ 47,448$ & $\$ 5,128$ & \multicolumn{3}{|l|}{$\$ 3,049$} & \\
\hline XII & 528 & $1.22 \%$ & $\$ 5,134$ & $\$ 9,723$ & 8,612 & $19.93 \%$ & $\$ 28,475$ & $\$ 3,307$ & \multicolumn{3}{|l|}{$\$ 971$} & \\
\hline XIII & 9,898 & $0.60 \%$ & $\$ 96,938$ & $\$ 9,794$ & 109,236 & $6.59 \%$ & $\$ 251,741$ & $\$ 2,305$ & \multicolumn{2}{|l|}{$\$ 966$} & & \\
\hline Total & 44,218 & $1.07 \%$ & $\$ 435,184$ & $\$ 9,842$ & 651,752 & $15.74 \%$ & $\$ 2,284,122$ & $\$ 3,505$ & \multicolumn{2}{|l|}{$\$ 1,708$} & & \\
\hline
\end{tabular}


Table 2. Changes in Headcount Ratios by Region

\begin{tabular}{|c|c|c|c|c|c|c|c|c|c|c|c|c|c|}
\hline & $\begin{array}{r}\text { Region } \\
\text { I }\end{array}$ & $\begin{array}{r}\text { Region } \\
\text { II }\end{array}$ & $\begin{array}{r}\text { Region } \\
\text { III }\end{array}$ & $\begin{array}{r}\text { Region } \\
\text { IV }\end{array}$ & $\begin{array}{r}\text { Region } \\
\mathrm{V}\end{array}$ & $\begin{array}{r}\text { Region } \\
\text { VI }\end{array}$ & $\begin{array}{r}\text { Region } \\
\text { VII } \\
\end{array}$ & $\begin{array}{r}\text { Region } \\
\text { VIII }\end{array}$ & $\begin{array}{r}\text { Region } \\
\text { IX } \\
\end{array}$ & $\begin{array}{r}\text { Region } \\
\mathrm{X}\end{array}$ & $\begin{array}{r}\text { Region } \\
\text { XI } \\
\end{array}$ & $\begin{array}{r}\text { Region } \\
\text { XII } \\
\end{array}$ & $\begin{array}{r}\text { Region } \\
\text { XIII }\end{array}$ \\
\hline Number of Counties & 10 & 9 & 9 & 15 & 38 & 33 & 30 & 52 & 31 & 42 & 10 & 11 & 52 \\
\hline \multicolumn{14}{|c|}{ Pre-Transfer Headcount Ratios } \\
\hline Maximum & $45.5 \%$ & $27.2 \%$ & $37.2 \%$ & $43.7 \%$ & $36.1 \%$ & $31.9 \%$ & $45.5 \%$ & $54.3 \%$ & $53.3 \%$ & $42.4 \%$ & $36.0 \%$ & $25.9 \%$ & $37.6 \%$ \\
\hline Minimum & $22.9 \%$ & $12.9 \%$ & $23.7 \%$ & $26.0 \%$ & $21.1 \%$ & $21.6 \%$ & $30.8 \%$ & $26.6 \%$ & $31.3 \%$ & $27.8 \%$ & $20.2 \%$ & $3.2 \%$ & $1.6 \%$ \\
\hline Median & $35.1 \%$ & $19.0 \%$ & $33.1 \%$ & $37.0 \%$ & $28.3 \%$ & $27.6 \%$ & $34.8 \%$ & $45.8 \%$ & $46.1 \%$ & $35.4 \%$ & $25.1 \%$ & $5.0 \%$ & $25.5 \%$ \\
\hline \multicolumn{14}{|c|}{ Change in Estimated Headcount Ratio } \\
\hline Median & $-19.7 \%$ & $-6.6 \%$ & $-11.9 \%$ & $-16.9 \%$ & $-9.3 \%$ & $-13.3 \%$ & $-17.7 \%$ & $-16.0 \%$ & $-18.2 \%$ & $-22.3 \%$ & $-28.3 \%$ & $-28.7 \%$ & $-7.5 \%$ \\
\hline Std. Dev. & $7.4 \%$ & $13.0 \%$ & $10.8 \%$ & $7.2 \%$ & $2.3 \%$ & $4.2 \%$ & $4.1 \%$ & $4.2 \%$ & $3.2 \%$ & $6.6 \%$ & $22.0 \%$ & $14.1 \%$ & $2.5 \%$ \\
\hline
\end{tabular}


Table 3. Correlates of Poverty Reduction at the County Level

\begin{tabular}{|c|c|c|c|}
\hline Variable & Unit & (1) & (2) \\
\hline Population & $\log$ & $0.00153^{* * *}(0.00012)$ & $0.00136^{* * *}(0.00014)$ \\
\hline Urban Share & $\%$ & $-0.06323^{* * *}(0.00348)$ & $-0.05350^{* * *}(0.00483)$ \\
\hline Mountains & $1 / 0$ & $0.00101^{* * *}(0.00017)$ & $0.00872^{* * *}(0.00152)$ \\
\hline Central Valley & $1 / 0$ & $-0.00426^{* * *}(0.00023)$ & $-0.00411^{* * *}(0.00034)$ \\
\hline Extreme Rainfall & $1 / 0$ & $-0.01210^{* * * *}(0.00114)$ & $-0.01221^{* * *}(0.00133)$ \\
\hline Region I x Urban Share & interaction & $-0.05207^{* * *}(0.00443)$ & $-0.06436^{* * *}(0.00708)$ \\
\hline Region II x Urban Share & interaction & $-0.15193^{* * * *}(0.03024)$ & $-0.15476^{* * *}(0.04872)$ \\
\hline Region III x Urban Share & interaction & $-0.14827^{* * * *}(0.00952)$ & $-0.15598^{* * *}(0.00838)$ \\
\hline Region IV x Urban Share & interaction & $-0.10081^{* * *}(0.00329)$ & $-0.11126^{* * *}(0.00457)$ \\
\hline Region V x Urban Share & interaction & $-0.04027^{* * * *}(0.00303)$ & $-0.05401^{* * *}(0.00426)$ \\
\hline Region VI x Urban Share & interaction & $-0.06344^{* * *}(0.00316)$ & $-0.07478^{* * *}(0.00439)$ \\
\hline Region VII x Urban Share & interaction & $-0.06358^{* * *}(0.00319)$ & $-0.07447^{* * *}(0.00457)$ \\
\hline Region VIII x Urban Share & interaction & $-0.05667^{* * *}(0.00304)$ & $-0.06484^{* * *}(0.00435)$ \\
\hline Region IX x Urban Share & interaction & $-0.05021^{* * *}(0.00322)$ & $-0.05951^{* * *}(0.00429)$ \\
\hline Region X x Urban Share & interaction & $-0.10270^{* * *}(0.00305)$ & $-0.11134^{* * *}(0.00408)$ \\
\hline Region XI x Urban Share & interaction & $-0.20490^{* * *}(0.00509)$ & $-0.21506^{* * *}(0.00649)$ \\
\hline Region XII x Urban Share & interaction & $-0.12343^{* * *}(0.00702)$ & $-0.13258^{* * *}(0.01384)$ \\
\hline Region I x Mountains & interaction & & $-0.02358^{* * *}(0.00410)$ \\
\hline Region II x Mountains & interaction & & $(0.00596)$ \\
\hline Region III x Mountains & interaction & & -0.00344 \\
\hline Region IV x Mountains & interaction & & $-0.00998^{* * *}(0.00174)$ \\
\hline Region V x Mountains & interaction & & $-0.01198^{* * *}(0.00147)$ \\
\hline Region VI x Mountains & interaction & & $-0.01138^{* * *}(0.00148)$ \\
\hline Region VII x Mountains & interaction & & $-0.01656^{* * *}(0.00154)$ \\
\hline Region VIII x Mountains & interaction & & $-0.00479^{* * *}(0.00148)$ \\
\hline Region IX x Mountains & interaction & & $-0.00724^{* * *}(0.00154)$ \\
\hline Region X x Mountains & interaction & & $-0.00572^{* * *}(0.00139)$ \\
\hline Region XI x Mountains & interaction & & $0.01507^{* * * *}(0.00441)$ \\
\hline Constant & & $0.11746^{* * *}(0.00249)$ & $0.10921^{* * *}(0.00407)$ \\
\hline Region dummies & & yes & yes \\
\hline Observations & & 341 & 341 \\
\hline $\begin{array}{l}\text { R-squared } \\
\text { No county in Regi }\end{array}$ & & 0.96 & 0.96 \\
\hline
\end{tabular}

